\title{
Response to Colombari et al. (2021)
}

\author{
Waney Squier ${ }^{1}\left[\right.$ D $\cdot$ Niels Lynøe ${ }^{2} \cdot$ Anders Eriksson $^{3}$
}

Received: 30 June 2021 / Accepted: 16 July 2021 / Published online: 12 August 2021

(c) The Author(s), under exclusive licence to Springer-Verlag GmbH Germany, part of Springer Nature 2021

Sir,

Colombari et al. [1] present a literature review to assess the contribution of spinal cord changes in differentiating abusive from accidental head trauma. This premise itself defies logic. Head trauma is head trauma. How can spinal cord pathology identify the intent of a perpetrator of such injury?

The opening statement "Shaking (with or without impact) has been identified as the leading mechanism resulting in the common AHT features, namely, the "triad" of intracranial subdural haematoma, cerebral oedema with hypoxic ischaemic changes and retinal haemorrhages" cites Squier [2]. Had the authors read even the abstract of that paper they will have seen "research has repeatedly undermined the hypothesis that shaking per se can cause this triad" followed by a discussion of the improbability of the shaking hypothesis concluding that "While shaking is no longer a credible mechanism for NAHI, there remains no doubt that inflicted head injury does occur". Such egregious misquotation of the first reference in the paper does not inspire confidence in anything that follows. Indeed, Lynøe et al. [3] are miscited, by stating that the triad is not sufficient to confirm abuse. Lynøe et al. were highly specific in addressing the lack of scientific evidence that the triad can be associated with traumatic shaking. They did not use the term abuse. Despite citing this study, Colombari et al. fail to acknowledge one of its main messages; that the child abuse literature is beset by circularity bias, thus invalidating the majority of the publications on which they depend.

Waney Squier

waney.squier@gmail.com

1 Formerly Department of Neuropathology, Oxford John Radcliffe Hospital, Oxford OX3 9DU, UK

2 Center of Healthcare Ethics, Karolinska Institute, Stockholm, Sweden

3 Department of Community Medicine and Rehabilitation, Forensic Medicine, Umeå University, Umeå, Sweden
The many claims that associations between particular medical findings and abuse have been "statistically proven" indicate that the authors fail to appreciate that medical science depends on observation and is not an exact science like mathematics; hence, it is very difficult to "prove" anything.

\section{Declarations}

W.S. and A.E. have given evidence for the prosecution and for the defence in cases of alleged child abuse.

Research involving human participants and/or animals N/A

Informed consent N/A

Conflict of interest The authors declare no competing interests.

\section{References}

1. Colombari M et al (2021) Spinal cord injury as an indicator of abuse in forensic assessment of abusive head trauma (AHT). Int J Legal Med 135(4):1481-98. https://doi.org/10.1007/ s00414-021-02526-x

2. Squier W (2011) The "shaken baby" syndrome: pathology and mechanisms. Acta Neuropathol. 122:519-542

3. Lynøe $\mathrm{N}$ et al (2017) Insufficient evidence for "shaken baby syndrome" - a systematic review. Acta Paediatr 106(7):1021-27. https://doi.org/10.1111/apa.13760

Publisher's note Springer Nature remains neutral with regard to jurisdictional claims in published maps and institutional affiliations. 